DOI: $10.4274 /$ tpa.46.03

\title{
Türkiye’deki 11, 13, 15 yaşındaki okul çocuklarının fiziksel etkinlik düzeylerinin demografik özellikler, beslenme alışkanlıkları ve hareketsiz yaşam davranışlarılyla ilişkisi
}

Relationship between physical activity level and demographic characteristics, eating habits and
sedantary behaviors of Turkish school children aged 11, 13 and 15 years

\author{
Ethem Erginöz, Müjgan Alikaşifoğlu* , Oya Ercan* , Ömer Uysal* * , Barış Ekici ${ }^{*}$, \\ Deniz Albayrak Kaymak***, Oktay Gülşah*, İlker Kemal Yücel ${ }^{*}$, Süheyla Ocak* \\ Istanbul Üniversitesi Cerrahpaşa Tıp Fakültesi Halk Sağlığı Anabilim Dalı, İstanbul, Türkiye \\ *istanbul Üniversitesi Cerrahpaşa Tıp Fakültesi Çocuk Sağlığı ve Hastalıkları Anabilim Dalı, İstanbul, Türkiye \\ ${ }^{*}$ Bezm-i Âlem Vakıf Üniversitesi Tıp Fakültesi Tıbbi İstatistik Tıbbi Bilişim Anabilim Dalı, İstanbul, Türkiye \\ ${ }^{* * \star}$ Boğaziçi Üniversitesi Eğitim Fakültesi, İstanbul, Türkiye
}

\begin{abstract}
Özet
Amaç: Bu araştırmanın amacı Türkiye'de okula devam etmekte olan ergenlerin fiziksel etkinlik düzeylerinin demografik etkenler, beden kitle indeksi ve bazı sağlık davranışları ile ilişkisini saptamaktı.

Gereç ve Yöntem: Bu çalışmada kesitsel tanımlayıcı ve çok uluslu "Health Behavior in School Aged Children (HBSC)" araştırmasının Türkiye ayağına katılan ve 6., 8. ve 10. sınıfa devam eden 11, 13 ve 15 yaşındaki ergenlerin verilerinin bir bölümü değerlendirildi. Veri çözümlemeleri 26 ildeki 82 ilkokulun 180 dersliğinde 11 ve 13 yaşlarındaki 3884 (1946 erkek, 1938 kız) ve 83 lisenin 88 dersliğinde 15 yaşındaki 1668 (901 erkek, 767 kız) öğrenci üzerinden yapıldı. İstatistiksel değerlendirmede ki-kare testi, faktör analizi ve lojistik regresyon analizi kullanıldı.

Bulgular: Öğrencilerin \%20'si haftada en az yedi gün, günde en az bir saat herhangi bir fiziksel etkinlikte bulunduklarını bildirdi. Çok değişkenli analizde (lojistik regresyon) fiziksel etkinlik ile erkek olmak, 15 yaşına göre 11 yaşında ve 13 yaşında olmak ve akşamları arkadaşları ile evin dışında zaman geçirmek arasında anlamlı ilişki bulundu. Beslenme davranışları hem sağlıklı hem de sağlıksız yiyecekleri az tüketenler esas alınarak incelendiğinde, diğer üç grubun (sağlıklı yiyecek tüketimi sık+sağlıksız yiyecek tüketimi seyrek olanlar; sağlıksız yiyecek tüketimi sık+sağlıklı yiyecek tüketimi seyrek olanlar; her iki tip yiyeceği sık tüketenler) esas gruba göre fiziksel etkinlik düzeylerinin daha fazla olduğu saptandı.

Çıkarımlar: Bu araştırmanın sonuçları ülkemizde yaşayan ergenlerin fiziksel etkinlik düzeylerinin yetersiz olduğunu, özellikle kızların fiziksel olarak etkin olmadığını, ergenlerin beslenme alışkanlıklarının ve arkadaşları ile geçirdikleri zamanın fiziksel etkinlik düzeyleriyle ilişkili olduğunu göstermesi açısından önemlidir. Etkin sağlığı koruma ve geliştirme programları özellikle kızlara odaklamalı ve ergenlerin beslenme alışkanlıklarının üzerinde durmalıdır. Akranların ergenlerin fiziksel etkinlik düzeylerinin artııımasında önemli rol oynayabilecekleri de unutulmamalıdır. (Türk Ped Arş 2011; 46: 12-9)

Anahtar sözcükler: Beslenme alışkanlıkları, ergen, fiziksel etkinlik, hareketsiz yaşam, şişmanlık

\section{Summary}

Aim: The aim of this study was to determine the relationships between physical activity level and demographic characteristics, body mass index and some other health behaviors in Turkish adolescents.

Material and Method: The data presented in this study were a part of the Turkish data collected for the cross-sectional and international "Health Behavior in School-aged Children 2005/2006 study" which aimed to evaluate adolescents' health and health behavior around Europe and North America. The data were collected from 388411 and 13 years of age (1946 males, 1938 females) students who attended 180 classes of 82 primary schools in 26 cities, and 166815 years of age (901 male, 767 female) students who attended 88 classes of 83 high schools in 26 cities. Statistical analyses were made by using chi square test, factor analysis and logistic regression analysis.
\end{abstract}

Yazışma Adresi/Address for Correspondence: Dr. Ethem Erginöz, İstanbul Üniversitesi, Cerrahpaşa Tıp Fakültesi Halk Sağlığı Anabilim Dalı Cerrahpaşa, İstanbul, Türkiye Türkiye E-posta: erginoze@gmail.com Geliş Tarihi/Received: 23.11.2010 Kabul Tarihi/Accepted: 30.12.2010 
Results: Twenty percent of the students reported that they were physically active at least 60 minutes a day every day a week. In logistic regression analysis being 11 and 13 years old, being male, spending four or more evenings with friends outside the home were found to be associated with being physically active. When the "eating both healthy and unhealthy foods less frequently group" was taken as the referans group, the other three groups (healthy foods frequently + unhealty foods less frequently; unhealthy foods frequently + healty foods less frequently; eating both healthy and unhealthy foods frequently) were more likely to be physically active than the reference group.

Conclusions: The results of this study are important to show that physical inactivity is common among Turkish adolescents especially females. These results are also important to show that both eating habits and time spent with friends are related to physical activity of the adolescents. Effective health promotion programme, should be especially focused on females and emphasize the importance of adolescents' eating habits. It should also be remembered that peers could play an important role to improve adolescents' physical activity level. (Turk Arch Ped 2011; 46: 12-9)

Key words: Adolescent, eating habits, obesity, physical activity, sedantary behavior

\section{Giriş}

Çocuk ve ergenlerin hareketsiz yaşam biçimini benimsemeleri evrensel bir sorundur. Dünya Sağlık Örgütünün 2004 yilı raporuna göre, dünya nüfusunun en az \%60'ı günde 30 dakika süreyle orta düzeyde fiziksel etkinlikte bulunmamaktadır (1).

"Health Behavior in School-aged Children (HBSC) araştırmasının 2006 raporu ülkeden ülkeye değişmekle beraber Avrupa ve Kuzey Amerika'da yaşayan okul çağı çocuklarının yeterli düzeyde fiziksel olarak etkin (orta-ağır) olmadığını gösterdi (2). Bu araştırmanın sonuçlarına göre en düşük fiziksel etkinlik düzeyleri 11 yaşındaki çocuklarda \%15 ile İsviçre'de, 13 yaşındaki çocuklarda \%12 ile Fransa'da ve 15 yaşındaki çocuklarda \% 8 ile İsrail'de saptandı (2).

Hareketsiz yaşamın şişmanlık, diyabet, koroner kalp hastalığı ve erken ölüm ile ilişkisi iyi bilinmektedir (3). Ayrıca ergenler açısından fiziksel etkinliğin en optimal büyüme gelişmeyi kolaylaştırdığı, kemik sağlığı açısından önemli olduğu (4) ve duygusal iyilik halini stres ve kaygıyı azaltarak geliştirdiği kabul edilmektedir (5-7).

Bu nedenle halk sağlı̆̆ı açısından ergenlerin fiziksel etkinlik düzeyi ile ilişkili etkenleri saptamak, sağlı̆ı korumak ve geliştirmek için etkin politikalar ve programlar geliştirilebilmesi önemlidir.

Çocuklar ve ergenler yetişkinlere göre fiziksel olarak daha etkin oldukları halde, şişmanlık sıklığının giderek artması (8), çocuk ve ergenlerin fiziksel etkinlik düzeylerinin yeterliliğinin sorgulanmasına yol açmışır (9). Bu nedenle çocuk ve ergenlerin haftanın her günü, günde en az bir saat orta düzeyde yoğun fiziksel etkinlikte (orta-ağır) bulunmaları önerilmiştir (9).

Araştırmalar birbirleriyle tutarlı olarak kızların fiziksel etkinlik düzeylerinin erkeklerden daha düşük olduğunu ve erken ergenlik döneminden genç erişkinliğe doğru ergenlerin fiziksel etkinlik düzeylerinin yaşla azaldığını göstermektedir (10-15). Sosyoekonomik düzey (SED) ile fiziksel etkinlik düzeyi arasındaki ilişkiyi inceleyen araştırmaların sonuçları ise değişkendir $(3,10,16,17)$. Fiziksel etkinlik düzeyi ile oturarak yapılan davranışlardan olan televizyon izleme ve bilgisayar kullanma süresi arasında farklı araştırmalarda farklı sonuçlar elde edilmiştir $(11,14,18-20)$. Yetersiz fiziksel etkinliğin şişmanlık ile ilişkisi de bazı araştırmalarda gösterilmiştir (12,21-24).

Bu araştırmanın amacı Türkiye'de okula devam etmekte olan ergenlerin fiziksel etkinlik düzeylerinin demografik etkenler, beden kitle indeksleri ve sağlıkla ilişkili davranışları (ev dışında geçirilen zaman, beslenme alışkanlıkları, oturarak yapılan davranışlar) ile ilişkisini saptamaktı.

\section{Gereç ve Yöntem}

Bu çalışmada gençlerin sağlık durumları ve sağlık davranışlarını saptamayı hedefleyen, kesitsel tanımlayıcı ve çok uluslu HBSC araştırmasının Türkiye ayağına katılan ve 6., 8. ve 10. sınıfa devam eden 11,13 ve 15 yaşındaki ergenlerin verileri değerlendirildi (2).

\section{Örneklem planı}

\section{Ögrrenci sayısının belirlenmesi}

Örneklemin oluşturulmasında T.C. Milli Eğitim Bakanlığı'nın (MEB) 2004 yııı verileri temel alındı. İlgilenilen yaş grubuna yeterli sayıda ulaşabilmek için o sınıfta o yaş grubunun gerçekten bulunma olasılığına göre (6. sınıf \%73; 8.sınıf \%70; 10. sınıf \%43) o sınıftaki öğrenci sayısı arttırılarak evren çerçevelendi. Anketteki en çok seçeneği olan sorunun 11 seçenekli oluşu, \%95 güven düzeyi (confidence level), \% 80 güç (power), 0,01 hata ve katman sayıları göz önüne alınarak örneklem sayısı belirlendi.

Altıncı ve 8. sınıf için (özel/resmi;kır/kent) dört katman, 10. Sınıf için (özel lise, genel lise, meslek lisesi) üç katman vardı. Belirlenen örneklem sayısı her sınıf için ayrı ayrı olmak üzere bu katmanlara dağıtıldı.

Örneklem birimi derslik idi. Altıncı ve 8. sınıflar için derslik başına düşen öğrenci sayısı resmi okulda 37 (kırda 25 , kentte 46), özel okulda ise 13 idi. Onuncu sınıflarda ise derslik başına genel liselerde 46 meslek liselerinde 27 özel liselerde ise dokuz öğrenci düşüyordu. Derslik dağılımı ise 
6. sınıf için özel okullarda beș derslik, resmi okullarda 90 derslik (kırdaki okullar 38 derslik, kentteki okullar 52 derslik), 8. sınıflar için özel okullarda dört derslik, resmi okullarda 82 derslik (kırdaki okullarda 34 derslik, kentteki okullarda 48 derslik) idi. Onuncu sınıflar için özel okullarda sekiz derslik, resmi okullarda 87 derslik (genel lise 45, meslek lisesi 42) idi.

Toplam 9388 öğrenciye ulaşılması hedeflendi. Örnekleme alınan öğrencilerin 3407'si (ulaşılması hedeflenen 11 yaşındaki öğrenci sayısı: 2487 idi.) 6. sınıfta (resmi okul= 3342; kır: 950; kent= 2392; özel okul= 65), 3110'u (ulaşılması hedeflenen 13 yaşındaki öğrenci sayısı 2177 idi). 8. sınıfta (resmi okul= 3058; kır: 850, kent=2208; özel okul=52) ve 2871'i (ulaşılması hedeflenen 15 yaşındaki öğrenci sayısı 1579 idi.) 10. sınıfta (özel lise= 72; resmi lise= 1665; meslek lisesi= 1134) idi. Katman, derslik ve yuvarlatma gibi düzeltmelerle elde edilen bu sayıya göre ortaya çıkan örneklem sayısına ait etki düzeyi (effect size) 1,44 olarak bulundu.

Bu örneklemden elde edilecek olan 11, 13 ve 15 yaşındaki ergenlerin Türkiye'de okula gitmekte olan 11, 13 ve 15 yaş grubu ergenleri temsil edeceği düşünüldü.

\section{il seçim ölçütleri}

Türkiye'de 81 "il" adı verilen yönetim bölgesi vardır. Örnekleme il seçilirken 12 bölgeli "The Nomenclature of Territorial Units for Statistics (NUTS)" NUTS-1 düzeyi temel alındı (25). İstanbul bölgesi ve Batı Anadolu bölgesi (Ankara alındı) dışında her bölgeden en az iki şehir örnekleme alındı. Bölgesinde değişik (heterojen) demografik özellikler gösteren iller kurasız örnekleme alındı. Aynı bölge içerisinde yukarıdaki özelliği gösteren iller dışında komşu iller örnekleme alınmadı.

\section{Uygulama}

\section{Soru formunun hazırlanması}

Özgün soru formunun İngilizce'den Türkçe'ye çevirisi ve sonrasında İngilizce'ye geri çevirisi dört farklı kişi tarafından yapıldı. İngilizce'ye geri çeviriler ile özgün soru formunun uygunluğu HBSC uluslararası eş güdümcü tarafından değerlendirildi ve önerileri doğrultusunda bazı sözcükler düzeltildi.

Pilot çalıșma İstanbul ilinde bir İlköğretim okulunun 6. sınıfları (iki sınıf, 63 öğrenci) ve bir lisenin 10. sınıfında (bir sınıf, 43 öğrenci) yapıldı. Soru formunun uygulanması sırasında gündeme gelen sorunlar ve sonrasında yapılan iki ayrı grup çalışmasından elde edilen sonuçlara göre bazı ifadeler düzeltildi.

\section{Soru formunun yapısı}

Health Behavior in School Aged Children araştırması zorunlu sorulardan ve kullanımı ülkelere bırakılmış seçmeli sorulardan oluşmaktadır (2). Uluslararası araştırma; sosyal eşitsizlik, pozitif sağlık, beden algısı ve ağırlık denetimi davranışları, kazalar ve yaralanmalar, șiddet ve zorbalık, yeme alışkanlıkları, akran kültürü, aile kültürü, okul ortamı, fiziksel etkinlik, boş zaman etkinlikleri, madde kullanımı (sigara, alkol ve uyuşturucu maddeler) ve cinsel sağlık başlıkları altında toplanmış ve uluslararası araştırma ekibinde yer alan odak grupları tarafından oluşturulan ya da benimsenen zorunlu ve seçmeli soruları içermektedir. Madde bağımlıı̆ı ve cinsel sağlıkla ilgili zorunlu sorular MEB tarafından onaylanmadığı için 11,13 ve 15 yaş grupları için hazırlanan (6, 8 ve 9 ya da 10. sınıf öğrencileri), Türkiye ekibinin kullandığı soru formlarında yer alamadı. On bir ve 13 yaș grubu (6. ve 8. sınıf öğrencileri) için hazırlanan soru formlarında yukarıda belirtilen sorular hariç sadece diğer zorunlu sorulara yer verildi. Onuncu sınıf (15 yaş) öğrencileri için hazırlanan soru formunda ise pozitif sağılı, aile kültürü, akran kültürü ve okul ortamına ait seçmeli sorulara da yer verildi. Altı ve 8 . sınıf öğrencileri için hazırlanan soru formunda toplam 42 soru başlığı, 10. sınıflara uygulanan soru formunda 62 soru bașlığı yer aldı.

\section{Okulların saptanması ve veri toplama așaması}

Derslikler, MEB'den elde edilen ve araștırmaya dahil edilmiş illere ait okul listeleri kullanılarak tesadüfi yöntemle okullara dağıtıldı. Her bir okul için başlangıçta bir yedek okul saptandı.

Her İlköğretim okulundan 6. ve 8. sınıf olmak üzere iki derslik tesadüfi yöntemle belirlendi. Derslik başına düşen öğrenci sayısı 20'nin altında kalan okullarda sınıf dengi oluşturmak üzere ikinci bir derslik örnekleme dahil edildi. Liselerde ise her bir okuldan tek bir derslik seçildi.

Araştırmaya alınan okulların müdürleri telefonla aranarak araştırma hakkında bilgi verildi. Veri toplama aşaması Mayıs 2006'da gerçekleştirildi. Soru formları okullara PTT aracılığı ile ulaştıııdı. Okullara soru formlarının yanı sıra MEB'in araştırma için verdiği izin yazısı, okul müdürlerine hitaben araștırmanın kapsamı ve uygulama sırasında dikkat edilmesi gereken noktaları açıklayan bir mektup, uygulamanın yapıldığı sınıflara ait gerekli bilgileri içeren bir form (sınıftaki öğrenci sayısı, uygulamaya katılan öğrenci sayısı vb.), uygulamayı yapacak sınıf öğretmenlerinin ya da rehber öğretmenlerin yararlanması için hazırlanmış standart bir yönerge ve iletişim bilgileri gönderildi. Okulların 17'sinden soru formları geri dönmedi. İki okul ellerine soru formlarının ulaşmadığını bildirdi. Üç okulda uygulama yapılmamıștı. On iki okula ait olup geri dönmeyen diğer soru formlarının PTT ile ilgili sorunlara bağlı olarak geri dönmediği düşünüldü.

\section{Ulaşılan öğrenci sayısı}

Toplam 8675 (ulaşma oranı \%92) öğrenciye ulașıldı. Bu öğrencilerden 2329'unun veri toplama tarihinde yaşları 11,13 ve 15 yaşlarının dışında kaldığından, 87'si doğum tarihini belirtmediğinden ve sekizi engelli olduğundan araştırma dışında bırakıldı. Anketin uygulandığı gün okulda olmayan öğrenci sayısı 656 ve araștırmaya katılmayı reddeden öğrenci sayısı 43 idi. Ulaşılan öğrencilerin 2072'si (hedefe göre ulaşma oranı \%83) 11 yaşında, 1812 'si (hedefe göre ulașma oranı \%83) 13 yașında ve 1668'i (hedefe göre ulaşılma oranı \%105) 15 yaşında idi. 
Sonuç olarak bu çalışmada veri çözümlemeleri 26 ildeki 82 ilköğretim okulunun, 180 dersliğinde 11 ve 13 yaşlarındaki 3884 (1946 erkek, 1938 kIz) ve 83 lisenin 88 dersliğinde 15 yaşındaki 1668 (901 erkek, 767 kız) öğrenci üzerinden yapıldı.

\section{Veri çözümlemeleri}

Bağımlı değişken olan fiziksel etkinlik düzeyi "orta-ağır" fiziksel etkinliği değerlendirmek üzere bir soru ile ölçüldü. Haftanın her günü günde en az 60 dakika fiziksel etkinlikte bulunanlar yeterli fiziksel etkinlikte (orta-ağır) bulunanlar olarak kabul edildi.

\section{Bağımsız değișkenler}

Öğrencilerin doğum tarihlerinden yaşları hesaplandı ve bu yaşlar üç kategoriye gruplandırıldı. Yerleșim yerleri okulların kırsal ya da kentsel alanda bulunuşuna göre iki gruba ayrıldı.

Kahvaltı etme sıklığı hafta içi ve hafta sonu için ayrı ayrı değerlendirildi. Veri çözümlemelerinde sadece hafta içi kahvaltı etme sıklı̆ı, "her gün kahvaltı edenler" ve "diğerleri" olmak üzere iki gruba ayrlarak, incelendi.

Sebze, meyve, şeker/çikolata ve şekerli gazlı içecek tüketim sıklığı ile ilgili dört soruya verilen yanıtların faktör analizi ile sağlıklı yiyecek tüketimi ve sağlıksız yiyecek tüketimi olarak iki gruba ayrıldığı görüldü. Bu nedenle beslenme gruplarının oluşturulmasında faktör puanları ölçüt olarak alındı. Faktör puanları sağlıklı yiyecek tüketimi grubunun en üst \%25'ine girenler "sağlıklı yiyecekleri sık tüketenler", faktör puanları sağlıksı yiyecek tüketme grubunun en üst \%25' ine girenler "sağlıksız yiyecekleri sık tüketenler" olarak kabul edilerek, her iki grup önce ikiye ayrıldı. Daha sonra öğrenciler her iki yiyecek tüketim sıklığı grubunda bulundukları yer değerlendirilerek dört gruba ayrıldılar.

1. Grup sağlıklı yiyecek tüketimi sık+sağlıksız yiyecek tüketimi seyrek olanlar

2. Grup sağlıksız yiyecek tüketimi sık+sağlıklı yiyecek tüketimi seyrek olanlar

3. Grup her iki tip yiyeceği sık tüketenler

4. Grup her iki tip yiyeceği seyrek tüketenler.

Diyet yapma sıklğı bir soru ile ölçüldü ve bu soruya "evet" diyenler ve "diğerleri" olarak gruplandırılarak çözümlemeler yapıldı.

Öğrencilere beden ağırlıkları ve boyları sorularak Beden Kitle İndeksleri (BKI) hesaplandı. Yaşa ve cinsiyete özgü uluslararası BKi kesme değerleri kullanılarak șişman ve fazla kilolu, normal ve zayıf grupları oluşturuldu (26). Normal ve zayıf grubuna giren öğrencilerin fiziksel etkinlik düzeyleri arasında fark saptanmadığından analizlere bu iki grup birleştirilerek alındı.

Öğrencilerin oturarak yaptıkları (sedanter) etkinlikleri televizyon izleme süreleri ve bilgisayarı ders dışı kullanım süreleri hafta içi ve hafta sonu için ayrı sorularla ölçülerek değerlendirildi. Öğrencilerin televizyon izleme ve bilgisayar kullanımı için hafta içi ve hafta sonunu birlikte kapsayan ağırlıklı ortalamaları hesaplandı. Her iki davranış için ayrı ayrı olmak üzere ortalamaları en üst \%25'e giren öğrenciler uzun süre televizyon izleyenler ve uzun süre bilgisayar kullananlar olarak kabul edildi.

Öğrencilerin arkadaşları ile akşamları evin dışında geçirdikleri zaman bir soru ile ölçüldü. Haftada en az dört akşam evin dışında arkadaşları ile vakit geçiren öğrenciler arkadaşları ile sık zaman geçirenler olarak kabul edildi.

Öğrencilerin ekonomik durumu "aile refah düzeyi" skalası (FAS- Family Affluence Scale) ile değerlendirildi. Aile refah düzeyi skalası ailenin araba sayısına, çocuğun kendine ait bir odasının olmasına, ailenin son 12 ay içinde tatile çıkma sıklığına ve evdeki bilgisayar sayısına verilen yanıtlara göre her çocuk için ayrı ayrı hesaplandı. Analizler için sıralı ölçek skalası geliştirildi. Bu skalaya göre FAS 1 (skor: 0-3) düşük refah; FAS 2 (skor: 4-5) orta düzeyde refah ve FAS 3 (skor: 6-7) yüksek refah düzeyini göstermektedir.

Tek değişkenli analizlerde ki kare testi kullanıldı. Çok değişkenli analizde ise fiziksel etkinlik düzeyini bağımsız olarak etkileyen değişkenleri saptamak üzere "enter" yöntemiyle lojistik regresyon analizi yapıldı. Her bir değişkenin kendi başına fiziksel etkinlik düzeyini etkileyeceği öngörüldüğünden, lojistik örneğe ikili karşılaştırmalardaki anlamllık düzeyine bakılmaksızın tüm değişkenler sokuldu.

İstatistik analizlerde SPSS 11,5 paket programı kullanıldı. Tüm karşılaştırmalarda $p<0,05$ düzeyi anlamlı olarak kabul edildi.

\section{Bulgular}

Fiziksel etkinlik sorusuna yanıt veren öğrenci sayısı 5254 idi. Öğrencilerin \%47,9'u ( $n=2515)$ kIz, \%52,1'i $(n=2739)$ erkekti. Araştırma grubunun \%37,3'ü 11 yaşında, \%32,6'sı 13 yaşında ve \%30,1'i 15 yaşında idi. Ergenlerin \% 80,1'i $(n=4207)$ kentsel, \%19,9'u ( $n=1047)$ kırsal yerleşim alanlarında yaşamaktaydı (Tablo 1).

Tablo 1. Çalışma grubunun sosyo-demografik özellikleri

\begin{tabular}{|lc|c|c|}
\hline & & $\mathbf{n}$ & $\%$ \\
\hline Cinsiyet & KIz & 2515 & $\% 47,9$ \\
\hline & Erkek & 2739 & $\% 52,1$ \\
\hline Yaş & 11 yaş & 1962 & $\% 37,3$ \\
\hline & 13 yaş & 1711 & $\% 32,6$ \\
\hline & 15 yaş & 1581 & $\% 30,1$ \\
\hline Yerleşim yeri & Kent & 4207 & $\% 80,1$ \\
\hline & Kı̈ & 1047 & $\% 19,9$ \\
\hline FAS $^{*}$ & Düşük & 3511 & $\% 69,2$ \\
\hline & Orta & 1282 & $\% 25,3$ \\
\hline & Yüksek & 278 & $\% 5,5$ \\
\hline
\end{tabular}

*FAS: Aile refah düzeyi skalası 
Öğrencilerin \%20'si ( $n=1055)$ haftanın her günü, günde en az bir saat herhangi bir fiziksel etkinlikte bulunduklarını bildirdi.

Fiziksel etkinlik ile sosyo-demografik değişkenler arasındaki ilişkiler Tablo 2'de sunulmuştur. Erkekler kızlara göre fiziksel olarak daha etkindi $(p<0,0001)$. Ergenlerin fiziksel etkinlik düzeyleri yaşla azalıyordu $(p<0,0001)$. Ergenlerin gereç zenginliği ve yerleşim yerleri ile fiziksel etkinlik düzeyleri arasında anlamlı ilişki bulunmadı.

\begin{tabular}{|c|c|c|c|c|c|c|}
\hline & & \multicolumn{2}{|c|}{$\begin{array}{c}\text { Fiziksel olarak } \\
\text { etkin }\end{array}$} & \multicolumn{2}{|c|}{$\begin{array}{l}\text { Fiziksel olarak } \\
\text { etkin değil }\end{array}$} & \multirow[b]{2}{*}{$p$} \\
\hline & & $\mathbf{n}$ & $\%$ & $\mathbf{n}$ & $\%$ & \\
\hline \multirow[t]{2}{*}{ Cinsiyet } & $\mathrm{KIz}$ & 433 & 17,2 & 2082 & 82,8 & 0,000 \\
\hline & Erkek & 622 & 22,7 & 2117 & 77,3 & \\
\hline \multirow{3}{*}{ Yaş } & 11 yaş & 498 & 25,4 & 1464 & 74,6 & \\
\hline & 13 yaş & 335 & 19,6 & 1376 & 80,4 & 0,000 \\
\hline & 15 yaş & 222 & 14 & 1359 & 86 & \\
\hline \multirow[b]{2}{*}{$\begin{array}{l}\text { Yerleşim } \\
\text { yeri }\end{array}$} & Kent & 859 & 20,4 & 3348 & 79,6 & \\
\hline & Kır & 196 & 18,7 & 851 & 81,3 & 0,22 \\
\hline \multirow{3}{*}{ FAS $^{*}$} & Düşük & 706 & 20,1 & 2805 & 79,9 & \\
\hline & Orta & 250 & 19,5 & 1032 & 80,5 & 0,277 \\
\hline & Yüksek & 66 & 23,7 & 212 & 76,3 & \\
\hline
\end{tabular}

*FAS: Aile refah düzeyi skalası
Sağlık davranışları ile fiziksel etkinlik ilişkisi Tablo 3'te verilmiştir. Ki kare testi sonuçlarına göre fiziksel olarak etkin olmak, hafta içi hergün kahvaltı etmek ile anlamlı olarak ilişkili bulundu $(p<0,001)$. Öğrencilerin fiziksel etkinlik düzeyi yiyecek tüketme örüntüsüne göre değişiyordu $(p<0,0001)$. Fiziksel olarak etkin ergenlerin arkadaşlarılya evin dışında daha fazla zaman geçirdikleri, daha uzun süre televizyon izledikleri ve bilgisayarı oyun amacıyla daha fazla kullandıkları saptandı (sırasıyla $p<0,0001, p=0,0002$, $\mathrm{p}=0,001$ ). Öğrencilerin diyet yapma davranışları ve BKi'leri ile fiziksel etkinlik düzeyleri arasında ilişki saptanmadı.

Çok değişkenli analiz (lojistik regresyon) sonuçları Tablo 4'te verilmiştir. Lojistik regresyon analizinde fiziksel etkinlik ile erkek olmak, 15 yaşına göre 11 ve 13 yaşında olmak akşamları arkadaşları ile evin dışında zaman geçirmek arasında anlamlı ilişki bulundu. Beslenme davranışları hem sağlıkı hem de sağlıksız yiyecekleri az tüketenler referans alınarak incelendiğinde, sağlıklı yiyecekleri seyrek, sağlıksız yiyecekleri sık tüketenler referans gruba göre 1,6 kat, sağılıkı yiyecekleri sık, sağlıksız yiyecekleri seyrek tüketenlerin referans gruba göre 1,65 kat ve her iki tip yiyecekleri sık tüketenlerin ise referans gruba göre 1,97 kat fiziksel olarak daha etkin oldukları saptandı. Tek değişkenli analiz sonuçlarına göre anlamlı görülen fiziksel etkin olanların daha çok televizyon seyretmesi ve bilgisayarda daha çok oyun oynaması çok değişkenli analizde anlamlı bulunmadı.

Tablo 3. Öğrencilerin sağlık davranışlarının fiziksel etkinlik ile ilişkisi

\begin{tabular}{|c|c|c|c|c|c|c|}
\hline & & \multicolumn{2}{|c|}{ Fiziksel olarak etkin } & \multicolumn{2}{|c|}{ Fiziksel olarak etkin değil } & \multirow[b]{2}{*}{$\mathbf{p}$} \\
\hline & & $\mathbf{n}$ & $\%$ & $\mathbf{n}$ & $\%$ & \\
\hline Kahvaltı yapmak & $\begin{array}{l}1-5 \text { gün } \\
\text { Hergün }\end{array}$ & $\begin{array}{l}360 \\
664\end{array}$ & $\begin{array}{l}17,8 \\
21,6\end{array}$ & $\begin{array}{l}1664 \\
2406\end{array}$ & $\begin{array}{l}82,2 \\
78,4\end{array}$ & 0,001 \\
\hline Diyet yapmak & $\begin{array}{l}\text { Evet } \\
\text { Hayır }\end{array}$ & $\begin{array}{l}60 \\
992\end{array}$ & $\begin{array}{l}24,7 \\
19,8\end{array}$ & $\begin{array}{l}183 \\
4007\end{array}$ & $\begin{array}{l}75,3 \\
80,2\end{array}$ & 0,065 \\
\hline Beslenme grupları & $\begin{array}{c}\text { SY*seyrek + SSY** seyrek } \\
\text { SYseyrek + SSYsık } \\
\text { SYsık + SSYseyrek } \\
\text { SYsık + SSYsık }\end{array}$ & $\begin{array}{l}480 \\
209 \\
219 \\
115\end{array}$ & $\begin{array}{l}16,4 \\
23,8 \\
25,6 \\
28,4 \\
\end{array}$ & $\begin{array}{l}2447 \\
668 \\
636 \\
290 \\
\end{array}$ & $\begin{array}{l}83,6 \\
76,2 \\
74,4 \\
71,6 \\
\end{array}$ & 0,000 \\
\hline Beden Kitle İndeksi & $\begin{array}{c}\text { Şişman +Fazla kilolu } \\
\text { Normal +Zayıf }\end{array}$ & $\begin{array}{l}98 \\
806\end{array}$ & $\begin{array}{l}20,9 \\
20,1\end{array}$ & $\begin{array}{l}370 \\
3204\end{array}$ & $\begin{array}{l}79,1 \\
79,9\end{array}$ & 0,668 \\
\hline $\begin{array}{l}\text { Arkadaşlarla } \\
\text { geçirilen zaman }\end{array}$ & $\begin{array}{l}\text { 0-3 akşam } \\
\geq 4 \text { akşam }\end{array}$ & $\begin{array}{l}852 \\
174\end{array}$ & $\begin{array}{l}19,2 \\
26,5\end{array}$ & $\begin{array}{l}3588 \\
482\end{array}$ & $\begin{array}{l}80,8 \\
73,5\end{array}$ & 0,000 \\
\hline Televizyon seyretmek & $\begin{array}{l}\geq 5,57 \text { saat } \\
<5,57 \text { saat }\end{array}$ & $\begin{array}{l}338 \\
668\end{array}$ & $\begin{array}{c}22,9 \\
19\end{array}$ & $\begin{array}{l}1138 \\
2852\end{array}$ & $\begin{array}{c}77,1 \\
81\end{array}$ & 0,002 \\
\hline $\begin{array}{l}\text { Bilgisayarla } \\
\text { oyun oynamak }\end{array}$ & $\begin{array}{l}\geq 3,71 \text { saat } \\
<3,71 \text { saat }\end{array}$ & $\begin{array}{l}318 \\
686\end{array}$ & $\begin{array}{l}23,8 \\
18,9\end{array}$ & $\begin{array}{l}1020 \\
2947\end{array}$ & $\begin{array}{l}76,2 \\
81,1\end{array}$ & 0,001 \\
\hline
\end{tabular}

SY*: Sağlıklı yiyecek

$S S Y^{\star *}$ : Sağlıksız yiyecek 


\section{Tartışma}

Araştırmamızın sonuçları Türkiye'deki ergenlerin büyük bölümünün fiziksel etkinliklerinin önerilen düzeyde olmadığını göstermektedir. Türkiye HBSC 2006 araştırmasında 41 ülke arasında fiziksel etkinlik açısından 11 yaş grubunda 20. sırada, 13 yaş grubunda 18. sırada ve 15 yaş grubunda 23. sırada yer almıştır (2). Bu sonuçlar fiziksel etkinliğin genel sağlık üzerine olumlu etkileri olduğu bilindiğinden önemlidir. Ayrıca çocukluk ve ergenlik çağındaki fiziksel etkinlik düzeyinin erişkin dönemdeki fiziksel etkinlik düzeyinin belirleyicisi olabileceği düşünüldüğünde, ergen sağlığını destekleme çalışmalarında öncelikli alanlardan biri olduğu kabul edilebilir.

Bu araştırmanın sonuçları erkek ergenlerin kız ergenlere göre 1,41 kat daha fazla fiziksel olarak etkin olduklarını göstermekteydi. Bu sonuç daha önce farklı ülkelerde yapılan araştırmaların sonuçlarına benzerdir $(10-13,15)$. Cinsiyet farkının nedeni sosyo-kültürel olarak erkeklerin fiziksel olarak etkin olmalarının kızlara göre daha fazla kabul görüyor olması olabilir. Araştırmalar kız ergenlerin ebeveynleri tarafından spor etkinliklerine katılma açısından daha az desteklendiklerini göstermiştir (27). Ayrıca erkekler oyun alanlarına ve spor sahalarına kızlardan daha kolay ulaşıyor olabilirler. Aynı zamanda fiziksel etkinlik düzeyinin biyolojik olgunlaşmayla da ilişkili olduğu ve bu nedenle kızların fiziksel etkinlik düzeyinin erkeklerden daha önce azaldığı, ancak farkın ileride kaybolduğunu gösteren araştırmalar da vardır (28). Sağlığı geliştirme programlarının etkinliğini artırabilmek için cinsiyet farkının nedenlerini araştıran niceliksel ve niteliksel araştırmalara gereksinim olduğunu düşünmekteyiz.

Araştırmamızda literatüre benzer olarak yaşla fiziksel etkinlik düzeyinin azaldığı saptandı $(10,12,13,15,29)$. Bu azalmada ergenlerin ilgi alanlarının farklılaşması, yaşça büyük ergenlerin spor yapabilecekleri tesisleri bulmakta zorlanmaları ve akademik yaşantılarına ayırdıkları zamanın artması gibi etkenler rol oynuyor olabilir. Oysa ki, özellikle kızlar açısından kemik yoğunluğunun ergenlik dönemi boyunca en iyi değerlere ulaşması ve bu nedenle fiziksel etkinlik düzeylerinin azalmadan devam etmesi oldukça önemlidir (4). Bu nedenle sağlığı geliştirme programlarında yaşça büyük ergenlere öncelik verilmesi ve aynı zamanda fiziksel etkinlik düzeyinin yaşla azalma nedenlerini saptayacak araştırmalar planlanması gerektiğini düşünmekteyiz.

Araştırmamızda hem sağılıklı yiyecekleri hem de sağlıksız yiyecekleri en sık tüketenlerin fiziksel olarak en etkin ergenler olduğu saptandı. Fiziksel etkinlik açısından ikinci sırada ise sağlıklı yiyecekleri sık, sağlıksız yiyecekleri seyrek olarak tüketenler yer aldı. Bu sonuçlar fiziksel olarak etkin ergenlerin beslenme alışkanlıkları açısından irdelenmesi gerektiğini düşündürdü. Fiziksel olarak etkin olan ergenlerin bir kısmı fiziksel etkinlik öncesinde ya da sonrasında enerji içeriği yüksek yiyecekleri tüketiyor olabilirler. Bunun yanı sıra meyve ve sebze tüketimine özen gösteriyor olabilirler. Nitekim sağlıklı yiyecekleri sık, sağlıksız yiyecekleri seyrek tüketen ergen grubunun da diğerlerine göre fiziksel olarak daha etkin bulunması fiziksel olarak etkin olanların sebze ve meyve tüketmeye özen gösterdikleri düşüncemizi doğrular niteliktedir. Literatürde sağlıklı beslenme ile fiziksel olarak etkin olma arasında ilişki olduğu gösterilmiştir (15).

Araştırmamızın tek değişkenli analizlerinde hafta içi her gün kahvaltı yapmak fiziksel etkin olmak ile ilişkili bulunmasına karşın çok değişkenli analizde ilişki bulunamadı. Daha önce yapılan araşıırmaların bir kısmında düzenli olarak kahvaltı yapanların fiziksel olarak etkinlik düzeylerinin yeterli olduğu gösterilmişken (30), bir kısmında gösterilmemiştir $(31,32)$. Bir araştırmada ise erkeklerde kahvaltı yapma ile sabah saatlerinde ya da günün diğer bölümlerindeki fiziksel etkinlik düzeyi arasında ilişki bulunmazken, kızlarda sabah saatlerindeki fiziksel etkinlik düzeyi kahvaltı yapma ile ilişkili bulunmuştur (33).

Araştırmamızda BKi ile ergenlerin fiziksel etkinlik düzeyleri arasında hem ikili karşılaştırmada hem de lojistik regresyon analizinde ilişki bulunmaması ilginçtir. Literatür incelendiğinde benzer sonuçlar $(14,15,34)$ ve tersine BKi'nin fiziksel etkinlik düzeyi ile ilişkili olduğunu gösteren araştırmalar vardır (21,22,35-37).

Tablo 4. Çok değişkenli analiz (lojistik regresyon) sonuçları

\begin{tabular}{|c|c|c|c|c|c|}
\hline & $\beta$ & $\mathbf{P}$ & $\operatorname{Exp}(\beta)$ & \multicolumn{2}{|c|}{ Güven aralığı (\%95) } \\
\hline Erkek olmak & 0,344 & 0,000 & 1,41 & $\begin{array}{c}\text { Alt sınır } \\
1,19\end{array}$ & $\begin{array}{c}\text { Üst sınır } \\
1,671\end{array}$ \\
\hline 11 yaşında olmak & 0,899 & 0,000 & 2,458 & 1,993 & 3,031 \\
\hline 13 yaşında olmak & 0,506 & 0,000 & 1,659 & 1,328 & 2,073 \\
\hline Arkadaşlarıyla fazla zaman geçirmek & 0,404 & 0,000 & 1,498 & 1,2 & 1,869 \\
\hline SY seyrek + SSY sIk & 0,475 & 0,000 & 1,607 & 1,295 & 1,996 \\
\hline SY sık + SSY seyrek & 0,501 & 0,000 & 1,651 & 1,333 & 2,046 \\
\hline SY sık + SSY sık & 0,681 & 0.000 & 1,976 & 1,503 & 2,597 \\
\hline
\end{tabular}

SY*: Sağlıklı yiyecek

SSY*: Sağlıksız yiyecek 
Araștırmamızda arkadașlarla evin dıșında zaman geçirme fiziksel etkinlik düzeyi ile ilişkili bulundu. Arkadaşlarla geçirilen zamanın niteliği incelenmemiş olmakta birlikte, ergenlerin çoğunlukla arkadaşları ile birlikte fiziksel etkinlikte bulundukları düşünüldüğünde bu bulgu, arkadașların fiziksel etkinlik düzeyinin bir belirleyicisi olduğunu düşündürebilir.

Araştırmamızda gereç zenginliği ile değerlendirilen SED, fiziksel etkinlik düzeyi ile ilişkili bulunmadı. Fiziksel etkinlikle SED ilişkisini inceleyen araştırmaların sonuçları değişkendir. Bazı araştırmalar sosyoekonomik düzeyi düşük olan ergenlerin fiziksel etkinlik düzeyinin yetersiz olduğunu göstermiştir $(10,13,16,17,27,38)$. Bazılarında ise sosyoekonomik düzeyle fiziksel etkinlik düzeyi arasında ilişki bulunamamıştır (39). Sosyoekonomik düzey gereç zenginliğinin yanı sıra anne-baba eğitimi ve anne-baba işi gibi farklı ölçütlerle değerlendirilebilmektedir. Bazı SED ölçütleri fiziksel etkinlikle ilişkili olabilirken, bazıları olmayabilir. Ayrıca ergenlik çağının bireylerin SED açısından az çok eșitlendiği bir evre olduğunu kabul edenler de vardır (2). Aynı zamanda bazı araştırmalar SED'den çok ebeveynlerin ve kardeşlerin fiziksel etkinlik düzeyinin ergenin fiziksel etkinlik düzeyinin bir belirleyicisi olduğunu göstermiştir $(15,39)$. Bu araştırmada diğer SED ölçütleri ve ebeveynlerin ve kardeşlerin fiziksel etkinlik düzeyleri araştııımadığından, bir çıkarım yapılmamıştır. Sosyoekonomik düzey fiziksel etkinlik düzeyi ilişkisinin ayrıntıı olarak incelenmesi gerektiğini düşünüyoruz.

Televizyon seyretme ve bilgisayar kullanımı fiziksel etkinliğin yerini alarak enerji dengesini bozabilir (40). Bazı araștırmalarda televizyon izleme ve bilgisayar kullanımı ile ergenlerin fiziksel etkinlik düzeyleri arasında ilișki bulunmuştur $(18,20)$. Bizim araştırmamızda ise tek değişkenli analizde anlamlı ilişki bulunduğu halde çok değişkenli analizde böyle bir ilişki saptanmadı. Benzer sonuçlar daha önceki birkaç araștırmada da elde edilmiștir $(11,14,19)$. Televizyon izleme ve bilgisayar kullanımı dıșında bașka oturarak yapılan davranışlar da olduğundan, bu davranışlar fiziksel etkinlikle ilişkili bulunmuyor olabilir.

\section{Kısıtıııklar}

Araștırmamızın kısıt|ııklarından biri öğrencilerin fiziksel etkinlik düzeylerinin kendi bildirimlerine dayanarak ölçülmüş olmasıdır. Bu nedenle kesin sıklığı yansıttığı söylenemeyebilir.

Fiziksel etkinlik düzeyinin mevsimsel değişim gösterdiğini gösteren çalışmalar vardır (41). Kıbrıs'ta illkokul çocuklarında yapılan bir araștırmada ise kırsal alanda yaşayan çocukların yaz aylarında, kentsel alanda yaşayan çocukların ise kış aylarında daha aktif oldukları saptanmıştır (41). Bizim araştırmamız Mayıs ayında yapıldığından, mevsimin etkisinin en az olacağı öngörülebilir.

\section{Sonuç}

Bu araștırmanın sonuçları ülkemizde yaşayan ergenlerin fiziksel etkinlik düzeylerinin yetersiz olduğunu, özellikle kızların fiziksel olarak etkin olmadığını, ergenlerin beslenme alışkanlıklarının ve arkadaşları ile geçirdikleri zamanın fiziksel etkinlik düzeyleriyle ilişkili olduğunu göstermesi açısından önemlidir. Etkin sağlığı koruma ve geliştirme programları özellikle kızlara ve yaşça büyük ergenlere odaklanmalı ve ergenlerin beslenme alışkanlıklarının üzerinde durulmalıdır. Akranların ergenlerin fiziksel etkinlik düzeylerinin artırılmasında önemli rol oynayabilecekleri de unutulmamalıdır.

\section{Çıkar çatışması: Bildirilmedi.}

\section{Kaynaklar}

1. World Health Organization. Benefits of physical activity Geneva: Switzerland; 2004. (Full Text)

2. Inequalities in young people's health: HBSC international report from the 2005/2006 Survey. Currie C, Gabhainn SN, Godeau E ed (s). Health Policy for Children and Adolescents. Copenhagen, WHO Regional Office for Europe 2006:5

3. Janssen I, Boyce WF, Simpson K, Pickett W. Influence of individual and area level measures of socioeconomic status on obesity, unhealthy eating, and physical inactivity in Canadian adolescents. Am J Clin Nutr 2006; 83: 139-45. (Abstract) / (Full Text) / (PDF)

4. McKay H, Liu D, Egeli D, Boyd S, Burrows M. Physical activity positively predicts bone architecture and bone strength in adolescent males and females. Acta Paediatr 2011; 1: 97-101. (Abstract) / (Full Text) / (PDF)

5. Kantomaa MT, Tammelin TH, Ebeling HE, Taanila AM. Emotional and behaviral problems in relation to physical activity in youth. Med Sci Sports Exerc 2008; 40: 1749-56. (Abstract)

6. Brosnahan J, Steffen LM, Lytle L, Patterson J, Boostrom A. The relation between physical activity and mental health among Hispanic and non-Hispanic white adolescents. Arch Pediatr Adolesc Med 2004; 158: 818-23. (Abstract) / (Full Text) / (PDF)

7. Volois RF, Zullig KJ, Huebner ES, Drane JW. Physical activity behaviors and perceived life satisfaction among public high school adolescents. J Sch Health 2004; 74: 59-65. (Abstract)

8. WHO. Obesity, preventing and managing the global epidemic. Geneva; World Health Organization, 1998.

9. Strong WB, Malina RM, Blimkie CJ, et al. Evidence based physical activity for school age youth. J Pediatr 2005; 146: 732-7. (Abstract) / (Full Text) / (PDF)

10. Inchley JC, Currie DB, Todd JM, Akhtar PE. Persistence sociodemographic differences in physical activity among Scottish schoolchildren 1990-2002. Eur J Public Health 2005; 15: 386-8. (Abstract) / (Full Text) / (PDF)

11. Samdal O, Tynjala J, Roberts C, Sallis JF, Villberg J, Wold B. Trends in vigorous physical activity and TV watching of adolescents from 1986 to 2002 in seven European Countries. Eur J Public Health 2007; 17: 242-8. (Abstract) / (Full Text) / (PDF)

12. Butte NF, Puyau MR, Adolph AL, Vohra FA, Zakeri I. Physical activity in nonoverweight and overweight Hispanic children and adolescents. Med Sci Sports Exerc 2007; 39: 1257-66. (Abstract)

13. Al Sabbah H, Vereecken C, Kolsteren P, Abdeen Z, Maes L. Food habits and physical activity patterns among palestinian adolescents: findings from the national study of Palestinian school children (HBSCWBG2004). Public Health Nut 2007; 10: 739-46. (Abstract) / (PDF)

14. Koluski DN, Mazengia GD, Shimony T, Goldsmith R, Berry EM. Prevalence and determinants of physical activity and lifestyle in relation to obesity among schoolchildren in Israel. Public Health Nut 2008; 12: 774-82. (Abstract) / (PDF)

15. Sallis JF, Prochaska JJ, Taylor WC. A review of correlates of physical activity of children and adolescents. Med Sci Sports Exerc 2000; 32: 963-75. (Abstract) / (PDF) 
16. Mota J, Santos R, Pereira M, Teixeira L, Santos MP. Perceived neighbourhood environmental characteristics and physical activity according to socioeconomic status in adolescent girls. Ann Hum Biol 2011; 38: 1-6. (Abstract) / (PDF)

17. Seabra AF, Mendonça DM, Thomis MA, Malina RM, Maia JR. Correlates of physical activity in Portuguese adolescents from 10 to 18 years. Scand J Med Sci Sports 2009; 9. (Epub ahead of print) (Abstract) / (Full Text) / (PDF)

18. Richards R, Poulton R, Reeder Al, Williams S. Childhood and contemporaneous correlates of adolescent leisure time physical inactivity: A longitudinal study. J Adolesc Health 2009; 44: 260-7. (Abstract) / (Full Text) / (PDF)

19. Kontogianni MD, Farmaki E, Vidra N, et al. Associations between lifestyle patterns and body mass index in a sample of Greek children and adolescents. J Am Diet Assoc 2010; 110 : 215-21. (Abstract) / (Full Text) / (PDF)

20. Robinson TN, Hammer LD, Killen JD et al. Does television viewing increase obesity and reduce physical activity? Cross-sectional and longitudinal analyses among adolescent girls. Pediatrics 1993; 91: 273-80. (Abstract)

21. Moayeri H, Bidad K, Aghamohammadi A, et al. Overweight and obesity and their associated factors in adolescents in Tehran, Iran 2004-2005. Eur J Pediatr 2006; 165: 489-93. (Abstract) / (PDF)

22. Ortega FB, Ruiz JR, Sjostorm M. Physical activity, overweight and central adiposity in Swedish children and adolescents: the European youth heart study. Int J Behav Nutr Phys Act 2007; 4: 61. (Abstract) / (Full Text) / (PDF)

23. Andersen RE, Crespo CJ, Bartlett SJ, Cheskin LJ, Pratt M. Relationship of physical activity and television watching with body weight and level of fatness among children. JAMA 1998; 279: 938-42. (Abstract) / (Full Text) / (PDF)

24. Fonseca $\mathrm{H}$, de Matos MG. Perception of overweight and obesity among Portuguese adolescents: an overview of associated factors. Eur J Public Health 2005; 15: 323-8. (Abstract) / (Full Text) / (PDF)

25. Türkiye İstatistik Yıllığı 2004. TC Başbakanlık Devlet İstatistik Enstitüsü. Ankara: Türkiye İstatistik Kurumu yayınları: 2004.

26. Cole TJ, Bellizzi MC, Flegal KM, et al. Establishing a standard definition for child overweight and obesity world wide: international survey. BMJ 2000; 320: 1-6. (Abstract) / (Full Text) / (PDF)

27. Dollman J, Lewis NR. The impact of socioeconomic position on sport participation among South Australian youth. J Sci Med Sport 2010; 13: 318-22. (Abstract) / (Full Text) / (PDF)

28. Cumming SP, Standage M, Gillison F, Malina RM. Sex differences in exercise behavior during adolescence: is biological maturation a confounding factor? J Adol Health 2008; 42: 480-5. (Abstract) / (Full Text) / (PDF)
29. Toftegard-Stockel J, Nielsen GA, Ibsen B, Andersen LB. Parental, socio and cultural factors associated with adolescents'sports participation in four Danish municipalities. Scand J Med Sci Sports 2010; 10. (Epub ahead of print) (Abstract) / (Full Text) / (PDF)

30. Magnusson MB, Hulthen L, Kjellgren KI. Obesity, dietary pattern and physical activity among children in a suburb with a high proportion of immigrants. J Human Nutr Dietet 2005; 18: 187-94. (Abstract) / (Full Text) / (PDF)

31. Mota J, Fidalgo F, Silva R, et al. Relationships between physical activity, obesity and meal frequency in adolescents. Ann Human Biol 2008; 35: 1-10. (Abstract) / (PDF)

32. Utter J, Scragg R, Mhurchu CN, Sxhaaf D. At-home breakfast consumption among New Zealand children: associations with body mass index and related nutrition behaviors. J Am Diet Assoc 2007; 570-6. (Abstract) / (Full Text) / (PDF)

33. Corder K, van Sluijs EM, Steele RM, et al. Breakfast consumption and physical activity in British adolescents. $\mathrm{Br} \mathrm{J}$ Nutr 2010; 1: 1-6. (Abstract)

34. Perez A, Reininger BM, Flores MIA, Maureen S, Roberts RE. Physical activity and overweight among adolescents on the Texas-Mexico border. Rev Punam Solud Publica 2006; 19: 244-52. (Abstract) / (Full Text) / (PDF)

35. Haug E, Rasmussen M, Samdal O, et al. Overweight in school-aged children and its relationship with demographic and lifestyle factors: results from the WHO-collabarative Health Behavior in School-aged Children (HBSC) Study. Int J Public Health 2009; 54: 162-79. (Abstract) / (Full Text) / (PDF)

36. Janssen I, Katzmarzyk PT, Boyce WF, King MA, Pickett W. Overweight and obesity in Canadian adolescents and their associations with dietary habits and physical activity patterns. J Adolesc Health 2004; 35: 360-7. (Abstract) / (Full Text) / (PDF)

37. Aeberli I, Kaspar M, Zimmermann MB. Dietery intake and physical activity of normal weight and overweight 6-to 14 year old Swiss children. Swess Med Wky 2007; 137: 424-30. (Full Text) / (PDF)

38. Sweeney NM, Glaser D, Tedeschi C. The eating and physical activity habits of inner-city adolescents. J Pediatr Health Care 2007; 21: 13-21. (Abstract) / (Full Text) / (PDF)

39. Voorheas CC, Catellier DJ, Ashwood JS, et al. Neighborhood socioeconomic status and non school physical activity and body mass index in adolescent girls. J Phys Act Health 2009; 6: 731-40. (Abstract) / (Full Text) / (PDF)

40. Epstein LH, Roemmich JN, Paluch RA, Raynor HA. Physical activity as a substitute for sedentary behavior in youth. Am Behav Med 2005; 29: 200-9. (Abstract)

41. Loucaides CA, Chedzoy SM, Bennett N. Differences in physical activity levels between urban and rural school children in Cyprus. Health Educ Res 2004; 19: 138-47. (Abstract) / (Full Text) / (PDF) 